\title{
Household Expenditures And Direct Medical Costs Among Older Adults In Ghana: Evidence From Who- sage Wave 2
}

\section{Paa-Kwesi Blankson}

Korle Bu Teaching Hospital

Sandra Ama Hewlett

University of Ghana

Thomas Akuetteh Ndanu

University of Ghana

Gyaami Amoah

University of Ghana

Matthew Owusu Boamah

Korle Bu Teaching Hospital

Daniel Tormeti

University of Ghana

Patrick Ampofo

University of Ghana

George Mensah

University of Ghana

Nadia Minicuci

National Research Council, Neuroscience Institute

Paul Kowal

World Health Organization Data, Analytics and Delivery for Impact

Margaret Lartey

University of Ghana

Richard Biritwum

University of Ghana

ALFRED YAWSON ( $\square$ aeyawson@ug.edu.gh )

UNIVERSITY OG GHANA

Research article

Keywords: Direct costs, health expenditures, household expenditures, older adults, Ghana, WHO-SAGE 
Posted Date: March 30th, 2020

DOl: https://doi.org/10.21203/rs.3.rs-18835/v1

License: (c) (i) This work is licensed under a Creative Commons Attribution 4.0 International License. Read Full License 


\section{Abstract}

Background: The Ghanaian population aged 60 years and older will almost double to reach $10 \%$ of the total population by 2050. Ascertaining the pattern of health expenditures among this growing population group is important to inform policy makers about the targets for financial risk protection as part of achieving Universal Health Coverage (UHC) by 2030. This study aimed to estimate household expenditures among older adults and determine the direct medical costs.

Methods: The World Health Organization's Study on global AGEing and adult health (SAGE) Wave 2 was conducted in China, Ghana, India, Mexico, Russian Federation, and South Africa between 2014 and 2015, as a follow-up to Wave 0 in 2003 to 2004 and Wave 1 in 2007 to 2010. Survey questions explored sources of income and total direct expenditures in the year preceding interview. SAGE Ghana was implemented using face-to-face interviews in a nationally representative sample of persons aged $50+$ years with a comparison sample of younger adults aged 18-49 years.

Findings : Analyses included a total of 4,735 participants, with 1,948 (41.1\%) males and 2,787 (58.9\%) females, of median and mean ages of 58 years and $57.6( \pm 16.7)$, respectively. The average annual household expenditures were US\$1,893.44 $( \pm 3,501.14)$. Older adults had higher expenditure levels at US\$ $1,902( \pm 3,876)$, as compared to younger adults, US\$1,867 $( \pm 1,937)$. Direct health-related costs and food expenditure accounted for $18 \%$ and $46 \%$ respectively of the total household expenditure of older Ghanaian adults. The prevalence of catastrophic health expenditure among older adults in Ghana was $4.5 \%(95 \% \mathrm{Cl} 3.5 \%$ to $5.8 \%)$

Conclusion: These updated estimates on household expenditure among older adults provide needed evidence to support the inclusion of social protection mechanisms in the national ageing agenda. The National Health Insurance as presently did not reduce the financial burden for households with older adults.

\section{Background}

The introduction of the National Health Insurance Scheme in 2003 has contributed to Ghana's targets to achieve Universal Health Coverage (UHC), although inequalities remain in health service coverage and financial risk protection (1). Older adults in Ghana are often at higher financial risk of impoverishing health expenditures as a result of often having greater health and long-term care needs than younger people.

The population aged 60 years and older in Ghana is currently $5.3 \%$ and is projected to reach $10 \%$ by 2050 $(2,3)$. The ageing population typically shifts disease burden patterns in countries, with increasing impact of age-related health conditions $(3,4)$.

A National Ageing Policy for Ghana (6) was adopted in 2010, seeking to achieve holistic social, economic and cultural re-integration of older people into mainstream society. It also sought to equip them to 
participate fully in the national development process. Enforcing social protection systems for this population group would be a crucial component of achieving the National Ageing Policy objectives, and would support older Ghanaians to get the health care services they need in the pursuit of Universal Health Coverage (UHC). Despite some comprehensive policies, not much has materialized towards implementing the National Ageing Policy and Implementation Action Plan $(7,8)$

Ascertaining the pattern of expenditure among this unique group does not only inform policy makers about heterogeneity in demand among older people, but gives an idea of how demand and costs are evolving in this population (9). A degree of ambiguity remains in the relationship between ageing populations and health care expenditure per person (10). The objective of this study is therefore to explore the levels and patterns of household expenditures in a nationally representative sample of Ghanaian households, with a focus on determining direct medical costs within overall expenditures.

\section{Methods}

\section{Data collection}

Data was obtained from the 2014/15 World Health Organisation (WHO) Study on global AGEing and adult health (SAGE) Ghana Wave 2. This included a follow-up sample from Wave 1, that consisted of nationally representative cohorts of adults aged 50 years and older, and smaller comparative samples of people aged 18-49 years (younger adults). Further information on SAGE, with country-specific household-level and person-level analysis weights, was made available by WHO (11).

\section{Participants, sampling and variables}

Recruitment of participants and implementation of the study was coordinated by the SAGE Ghana Team. SAGE Ghana employed a stratified random sampling strategy with households as the final sampling units (12). More details about the sampling strategies are available elsewhere (13). The sociodemographic characteristics information collected included age, sex, educational level, financial assistance, marital status and health insurance. Participants also self-assessed their perception of health as being 'Very Good', 'Good', 'Moderate', 'Bad', or 'Very Bad'. Outcome variables were total household expenditures and total direct medical costs over the year preceeding the interview, generated by the variables listed in Table 1.

\section{Data analysis}

Total direct medical costs and total household expenditures were estimated by summing the costs of the individual categories (Table 1). Variables which were ascertained for a 30-day period were multiplied by 12 to obtain estimates of annual costs. All estimated costs were converted into US\$ using an exchange rate of GHS 3.21 (the exchange rate at the time this study was conducted). The catastrophic health expenditure was also determined as the ratio of health care to total household consumption expenditures, 
and defined as a proportion of the number of participants with direct health costs accounting for $40 \%$ or more of the total household expenditure $(13,14)$.

\section{All variables were analyzed using Stata (Version 14). Descriptive statistics were used to describe participant characteristics. Student's t-test was used to compare outcome mean values between groups and Chi-square test was used to test association between categorical variables, with an alpha level of 0.05 .}

Table 1: Description of input variables for the selected analytical outcomes

\begin{tabular}{|c|c|c|}
\hline $\begin{array}{l}\text { ppendent } \\
\text { riable }\end{array}$ & Category & Description \\
\hline \multirow[t]{11}{*}{$\begin{array}{l}\text { rect } \\
\text { sts }\end{array}$} & Consultations & $\begin{array}{l}\text { Registration and consultation fees by doctors, nurses, or trained midwives that did not require } \\
\text { an overnight stay }\end{array}$ \\
\hline & $\begin{array}{l}\text { Traditional or alternative } \\
\text { health care }\end{array}$ & Care by traditional or alternative healers \\
\hline & Investigations & Diagnostic and laboratory tests such as X-rays or blood tests \\
\hline & Medications & $\begin{array}{l}\text { Medications or drugs form prescription, non-prescription, traditional, homeopathic } \\
\text { practitioners }\end{array}$ \\
\hline & Dental & Oral and dental care \\
\hline & $\begin{array}{l}\text { Mandatory health } \\
\text { insurance }\end{array}$ & Mandatory health insurance premiums or pre-paid health plans \\
\hline & $\begin{array}{l}\text { Voluntary health } \\
\text { insurance premiums }\end{array}$ & Voluntary health insurance premiums (including, community health insurance schemes \\
\hline & Health-related items & Items such as prescription glasses, hearing aids, canes, prosthetic devices \\
\hline & Overnight stays & Costs associated with overnight stays in a hospital or health facility \\
\hline & Care facility & Costs associated with long-term care facility \\
\hline & Others & Any other health care products or services that were not included above \\
\hline \multirow{9}{*}{$\begin{array}{l}\text { tal household } \\
\text { penditure }\end{array}$} & Food & \\
\hline & Housing and utilities & Rent, mortgage, electricity, heating/cooking fuel, water, telephone \\
\hline & Clothing & $\begin{array}{l}\text { Footwear, hats, shirts, pants, dresses, skirt, jackets, coat and other personal items, such as } \\
\text { soap, shampoo, cosmetics, shaving cream etc. }\end{array}$ \\
\hline & Transportation & Bus fares, cab/taxi fares, vehicle repair costs, petrol \\
\hline & $\begin{array}{l}\text { Recreation } \\
\text { entertainment }\end{array}$ & Expenditure on entertainment and recreation \\
\hline & Education & Costs of educational fees and supplies, such as tuition, course fees and books \\
\hline & Durable goods & $\begin{array}{l}\text { Televisions, phones, bed sheets, towels, tools, furniture (tables, chairs, beds) and appliances } \\
\text { (refrigerators, washing machines }\end{array}$ \\
\hline & Taxes & $\begin{array}{l}\text { Property tax, vehicle tax, income tax, etc and non-health related insurance (personal, vehicle, } \\
\text { household, life) }\end{array}$ \\
\hline & Others & All other goods and services aside health related ones which are not listed above \\
\hline
\end{tabular}

\section{Results}

A final sample of 4,735 was used for analysis. This consisted of 1,948 (41.1\%) males and $2,787(58.9 \%)$ females ranging from 18 years to 110 years with median and mean ages of 58 years and $57.6( \pm 16.7)$ respectively. Nearly three-quarters $(75.5 \%)$ of the participants were 50 years or older (Table 2 ). Over a quarter $(26.1 \%)$ of the participants had received financial assistance within the past year (Figure 1). Of 
these, 1063 (43\%) were in the older adult group, compared to $165(16.9 \%)$ of the younger adult population $(P<0.001)$. Similarly, most of the participants with no formal education were older adults $(49.9 \%)$, compared to the $18.3 \%$ of the younger adult population $(P<0.001)$. Older adults were significantly more likely than younger adults to perceive their health to be either 'bad' or 'very bad' ( $O R=3.9, P<0.001)$. The marital status and health insurance coverage distribution among older adult age groups did not vary significantly.

The average annual household expenditures among adults in Ghana varied considerably among different subgroups (Table 2). However, the average expenditure per annum for the entire population was US\$ $1,893.44 \pm 3,501.14$, with a US\$ $318 \pm 2,736$ average annual expenditure on health. Direct medical costs accounted for $16.8 \%$ of the total household expenditures with levels different for younger $(12.5 \%)$ and $18.1 \%$ among the older adults. The proportions of the household expenditure components among older adults are shown in Figure 2. The prevalence of catastrophic health expenditure among older people in Ghana was $4.5 \%(95 \% \mathrm{Cl} 3.5 \%-5.8 \%)$. That of the entire population was however $4.9 \%(95 \% \mathrm{Cl} 3.9 \%$ $6.0 \%)$.

Comparing the pattern of direct medical costs and total expenditure across the sociodemographic characteristics, the average household expenditure differed significantly among educational levels, as well as marital status. The same observation was made for the average direct medical cost among subpopulations for having received financial assistance or not (Table 2). Out-of-pocket expenditures on transportation and traditional or alternative health therapies were higher among older adults, compared to the younger adult population. Though not significant, the inverse was observed for expenditurs on medications, dental care, food, housing and utilities (Table 3).

Table 2: Average expenditure across participant sociodemographic characteristics, SAGE Ghana Wave 2. 


\begin{tabular}{|c|c|c|c|c|c|c|c|}
\hline ıriable & $\begin{array}{l}\text { Number } \\
\text { (n) }\end{array}$ & $\begin{array}{l}\text { Percent } \\
(\%)\end{array}$ & $\begin{array}{l}\text { Avergae Annual Expenditure } \\
\text { (SD) }\end{array}$ & $\begin{array}{l}\mathrm{P}- \\
\text { value }\end{array}$ & $\begin{array}{l}\text { Average Health } \\
\text { Expenditure (SD) }\end{array}$ & $\begin{array}{l}\mathrm{P}- \\
\text { value }\end{array}$ & $\begin{array}{c}\text { Catastrophic } \\
\text { Expendituret } \\
(\%)\end{array}$ \\
\hline $3 x$ & & & $2,071 \pm 4,332$ & 0.115 & & 0.322 & \\
\hline Male & 1,948 & 41.1 & $1,785 \pm 2,879$ & & $405 \pm 3,572$ & & 4.3 \\
\hline Female & 2,787 & 58.9 & & & $264 \pm 2,069$ & & 5.2 \\
\hline je categories & & & $1,867 \pm 1,937$ & 0.865 & & 0.491 & \\
\hline Less than 50 & 1,160 & 24.5 & $1,902 \pm 3,876$ & & $234 \pm 792$ & & 5.9 \\
\hline 50 and older & 3,575 & 75.5 & & & $345 \pm 3,116$ & & 4.5 \\
\hline nancial assistance & & & $2,116 \pm 5,607$ & 0.142 & & $0.016^{*}$ & \\
\hline$=4,674)$ & 1,228 & 26.1 & $1,818 \pm 2,402$ & & $601 \pm 5,176$ & & 5.2 \\
\hline Yes & 3,446 & 73.3 & & & $222 \pm 969$ & & 4.7 \\
\hline \multicolumn{8}{|l|}{ No } \\
\hline rrmal Education & & & $1,353 \pm 1,773$ & $0.021 *$ & & 0.327 & \\
\hline None & 1,996 & 42.5 & $1,658 \pm 2,191$ & & $183 \pm 1,129$ & & 4.9 \\
\hline Less than primary & 653 & 23.8 & $2,203 \pm 2,704$ & & $147 \pm 451$ & & 2.3 \\
\hline Primary school & 701 & 25.6 & $2,132 \pm 4,420$ & & $301 \pm 919$ & & 6.5 \\
\hline Secondary school & 707 & 25.8 & $3,164 \pm 7,200$ & & $429 \pm 3,752$ & & 3.5 \\
\hline High school & 524 & 19.1 & $2,805 \pm 2,538$ & & $941 \pm 6,503$ & & 8.2 \\
\hline University & 147 & 5.4 & $3,816 \pm 943$ & & $187 \pm 226$ & & 2.0 \\
\hline Post graduate & 7 & 0.3 & & & $520 \pm 512$ & & - \\
\hline If-reported health & & & $1,707 \pm 2,007$ & 0.113 & & 0.616 & \\
\hline Very good & 651 & 13.9 & $2,116 \pm 4,278$ & & $309 \pm 1,443$ & & 3.5 \\
\hline Good & 2,541 & 54.1 & $1,677 \pm 2,655$ & & $424 \pm 3,820$ & & 4.7 \\
\hline Moderate & 1,114 & 23.7 & $1,542 \pm 2,517$ & & $186 \pm 528$ & & 5.1 \\
\hline Bad & 329 & 7.0 & $2,682 \pm 5,359$ & & $150 \pm 292$ & & 7.3 \\
\hline Very bad & 61 & 1.3 & & & $319 \pm 649$ & & 6.7 \\
\hline arital status & & & $2,104 \pm 3,971$ & $0.008^{*}$ & & 0.372 & \\
\hline Married/cohabiting & 2,693 & 56.9 & $1,636 \pm 2,806$ & & $373 \pm 3,056$ & & 4.2 \\
\hline Single & 2,042 & 43.1 & & & $250 \pm 2,286$ & & 5.6 \\
\hline zalth Insurance & & & $1,969 \pm 3,960$ & 0.158 & & 0.113 & \\
\hline Yes & 3,449 & 73.0 & $1,690 \pm 1,742$ & & $384 \pm 3,191$ & & 5.0 \\
\hline None & 1,276 & 27.0 & & & $139 \pm 465$ & & 4.4 \\
\hline
\end{tabular}

US\$1.00 equivalent to GHS3.21 (Bank of Ghana average monthly interbank exchange rate, December 2014)

Table 3: Pattern of expenditure among adults in Ghana, SAGE Ghana Wave 2, 2015

\begin{tabular}{lccc}
\hline Cost area & Less than $\mathbf{5 0}( \pm \mathrm{SD})$ & $\mathbf{5 0}$ and older $( \pm \mathrm{SD})$ & P-value \\
\hline Traditional/alternative health care & $84.75 \pm 78.77$ & $129.89 \pm 302.59$ & 0.822 \\
\hline Medications & $166.68 \pm 589.91$ & $130.96 \pm 355.82$ & 0.208 \\
\hline Dental & $47.24 \pm 22.27$ & $40.10 \pm 28.36$ & 0.377 \\
\hline Food & $895.37 \pm 938.41$ & $861.81 \pm 1,068.64$ & 0.580 \\
\hline Housing and utilities & $1,335.26 \pm 21,510.42$ & $169.58 \pm 307.80$ & 0.071 \\
\hline Clothing & $112.02 \pm 163.03$ & $96.63 \pm 245.38$ & 0.248 \\
\hline Transportation & $139.03 \pm 137.06$ & $151.58 \pm 350.48$ & 0.759 \\
\hline
\end{tabular}

\section{Discussion}


This study set out to determine the pattern of expenditure among older adults in Ghana, while ascertaining their direct medical costs. The results from this study comes as pertinent for several reasons, especially in a low-middle income country such as Ghana and similar counties in the subregion. Ghana has shown a gradual change in its demographic characteristics due to population ageing (16). The somewhat gradual pace provides valuable lead time for strategic planning and policy development to ensure systems are prepared for the coming changes. Estimates of household expenditure, such as those from this study, could therefore be used to inform policies, with regards to prioritization, health insurance, reimbursements, social services, housing, transportation and agriculture among older persons. Despite considerable attempts to include as many older Ghanaians as possible onto the NHIS, among other policies (8), this study suggests that the NHIS did not significantly reduce the average household expenditure, nor the direct cost on health for households with older adults. These results will therefore feed into efforts to refine and extend coverage of the NHIS so that older adults are included in UHC targets.

It is important to establish that though the pattern of household expenditure holds great predictive value in planning, it is affected by many individual preferences which may be difficult to account for (behavioural heterogeneity) (9). There are also assertions of age-associated health conditions which could increase the household expenditures among older adults.

This study found the average household cost among the study participants to be US\$1,893. These low estimates, though excluding taxes, are considered characteristic of low income countries which Ghana was, at the time of the study. Furthermore, the average direct medical cost, being US\$318, accounted for $18.1 \%$ of the average total expenditure among the elderly. It has been suggested that at low income levels, spending diversity is low, as food and health care might be expected to dominate spending (9). In corroboration with this, food and healthcare took a proportionate $46 \%$ and $18.1 \%$ of the total household expenditure among the elderly in this study, the highest among the variables investigated. In comparison to these, average annual health expenditure was estimated to be US\$7,439 among older populations in Australia at about the time of this study (10). Also, in this study, $7 \%$ of household income was accrued by medications, while an equal amount was spent on herbal/alternative medicines. This further substantiates the high prevalence of alternative/traditional medicine usage among older Ghanaian adults (17).

Aside being a LMIC, the pattern of expenditure among older Ghanaians generally differs from that that of Japan (18), UK (1,14), and the USA (20), due to the entire prevailing social, political and cultural systems. For instance health financing in Ghana is mainly publicly funded through the National Health Insurance scheme (NHIS), which as of the commencement of this study in 2014, covered some 10.4 million Ghanaians, approximating $40 \%$ of the country's population (21). The fairly large coverage, which is free for adults aged 70-plus years, and the 'core poor' defined as the unemployed with no visible source of income, no fixed residence, and not living with someone employed and with a fixed residence (22), could significantly have contributed to the comparatively lower out-of-pocket expenditure on health. Also, Ghana has a deep-rooted housing crises which has seen several attempts at reforms over the past few 
decades (23). With rising cost of rent, cheaper alternatives and settlements, especially in rural areas could be the preference among older adults. The $16 \%$ 'Other' category (Fig. 1) could be a reflection of the heterogeneity of the study population. Included in this category are taxes, gifts, recreation, among others.

Safeguarding people from catastrophic payments, that is, financial hardship caused by health payments, has come to be a widely accepted index, and a desirable objective in health policy. This study found the prevalence of catastrophic health expenditure among older adults in Ghana to be $4.5 \%$, using a $40 \%$ threshold. As catastrophic health spending is generally thought to be rising, our figure relates to the $7 \%$ prevalence found in India (15). Over a quarter of the participants had obtained financial assistance, while many of the participants (30\%) had salaries being the major source of financing. A significant $34 \%$ of older population had to borrow money or sell their property to finance their expenditure. Nearly half of the older population had also not had any formal education, an observation which could inform the policy process and its implementation.

\section{Conclusion}

This study in many ways highlights the unmet need for social support for older Ghanaians. In providing estimates and pattern of the expenditure of this group, detailed planning could be incorporated into social interventions. Findings from this study could also be used in hypotheses generation for future studies to explore how the older population in Ghana is evolving.

\section{Abbreviations}

LMIC: Lower-Middle Income Countries; NHIS: National Health Insurance Scheme; WHO: World Health Organization; SAGE: Study on global AGEing and adult health; UHC: Universal Health Coverage

\section{Declarations}

We the undersigned declare that this manuscript is original, has not been published before and is not currently being considered for publication elsewhere.

We wish to confirm that there are no known conflicts of interest associated with this publication and there has been no significant financial support for this work that could have influenced its outcome. We confirm that the manuscript has been read and approved by all named authors and that there are no other persons who satisfied the criteria for authorship but are not listed. We further confirm that the order of authors listed in the manuscript has been approved by all of us.

We confirm that we have given due consideration to the protection of intellectual property associated with this work and that there are no impediments to publication, including the timing of publication, with respect to intellectual property. In so doing we confirm that we have followed the regulations of our institutions concerning intellectual property. We understand that the Corresponding Author is the contact for the Editorial process (including Editorial Manager and direct communications with the office). He is 
responsible for communicating with the other authors about progress, submissions of revisions and final approval of proofs. We confirm that we have provided a current, correct email address which is accessible by the Corresponding Author and which has been configured to accept email from BMC Public Health.

Signed by all authors as follows:

Dr. Paa-Kwesi Blankson

Dr. Sandra Hewlett

Dr. Thomas Akuetteh Ndanu

Dr. Gyaami Amoah

Dr. Matthew Owusu Boamah

Dr. Daniel Tormeti

Dr. Patrick Ampofo

Dr. George Mensah

Prof. Nadia Minicuci

Dr. Paul Kowal

Prof. Margaret Lartey

Prof. Richard Biritwum

Prof. Alfred Yawson

\section{Funding}

WHO SAGE was funded by the World Health Organization, the US National Institute on Aging through Interagency Agreements (OGHA 04034785; YA1323-08-CN-0020; Y1-AG-1005-01) and through a research grant (R01-AG034479), and the University of Ghana.

\section{Authors' contributions}

AY, SH and PKB conceptualized and designed the study. PKB and $\mathrm{SH}$ were responsible for extraction of data. PKB, SH, NM, KP, ML and AY analyzed and interpreted the data. All authors drafted, read and approved the final manuscript.

\section{Ethical requirements}


SAGE was approved by the World Health Organization's Ethical Review Board (reference number RPC149) and the Ethical and Protocol Review Committee, College of Health Sciences, University of Ghana, Accra, Ghana. Written informed consent was obtained from all study participants.

\section{Consent for publication}

Not applicable

\section{Declaration of interests}

The authors declare that there are no conflicts of interest regarding the publication of this article

\section{References}

1. Zhang C, Rahman MS, Rahman MM, Yawson AE, Shibuya K. Trends and projections of universal health coverage indicators in Ghana, 1995-2030: A national and subnational study. Rockers P, editor. PLoS One. 2019;14(5):e0209126.

2. Kpessa-Whyte M. Aging and Demographic Transition in Ghana: State of the Elderly and Emerging Issues. Gerontologist. 2018;58(3):403-8.

3. UNDESA. World Population Prospects 2019: Highlights. Futuribles. 2019;(141):2-3.

4. WHO | Health statistics and information systems. WHO. 2018.

5. Biritwum RB, Mensah G, Minicuci N, Yawson AE, Naidoo N, Chatterji S, et al. Household characteristics for older adults and study background from SAGE Ghana Wave 1. Glob Health Action. 2013;6:20096.

6. National Ageing Policy 'Ageing With Security And Dignity': Ministry of Gender, Child and Social Protection. 2010. Available from: http://mogcsp.gov.gh/index.php/mdocs-posts/national-ageingpolicy-ageing-with-security-and-dignity/

7. Nortey ST, Aryeetey GC, Aikins M, Amendah D, Nonvignon J. Economic burden of family caregiving for elderly population in southern Ghana: the case of a peri-urban district. Int $J$ Equity Health. 2017;16(1):16.

8. World Health Organization. Ghana country assessment report on ageing and health. Ghana Ctry Assess Rep ageing Heal. 2014;1-44.

9. Chai A, Rohde N, Silber J. Measuring the Diversity of Household Spending Patterns. 2013. Available from: https://core.ac.uk/download/pdf/143877460.pdf

10. Harris A, Sharma A. Estimating the future health and aged care expenditure in Australia with changes in morbidity. Callander E, editor. PLoS One. 2018;13(8):e0201697.

11. Kowal P, Chatterji S, Naidoo N, Biritwum R, Fan W, Ridaura RL, et al. Data resource profile: The world health organization study on global ageing and adult health (SAGE). Int J Epidemiol. 2012 Dec;41(6):1639-49. 
12. Fan W, Arokiasamy P, Lopez Ridaura R, Maximova South Africa T, Phaswanamafuya R. Response rates HH Response Rate \% HH Cooperation Rate \% IND Response Rate \% IND Cooperation Rate \%. Available from: https://www.who.int/healthinfo/sage/SAGEWorkingPaper5_Wave1Sampling.pdf? ua $=1$

13. Naidoo N. SAGE Working Paper No. 5. WHO Study on global AGEing and adult health (SAGE) Waves 0 and 1 - Sampling information for China, Ghana, India, Mexico, Russia and South Africa., World Health Organisation. World Heal Organ. 2012;1-9.

14. Xu K, Evans DB, Kawabata K, Zeramdini R, Klavus J, Murray CJL. Household catastrophic health expenditure: A multicountry analysis. Lancet. 2003;362(9378):111-7.

15. Brinda EM, Kowal P, Attermann J, Enemark U. Health service use, out-of-pocket payments and catastrophic health expenditure among older people in India: The WHO study on global AGEing and adult health (SAGE). J Epidemiol Community Health. 2015;69(5):489-94.

16. Tawiah EO. Population ageing in Ghana:a profile and emerging issues. African Popul Stud. 2011;25(2).

17. James PB, Wardle J, Steel A, Adams J. Traditional, complementary and alternative medicine use in Sub-Saharan Africa: a systematic review. BMJ Glob Heal. 2018;3(5):e000895.

18. Harris A, Sharma A. Estimating the future health and aged care expenditure in Australia with changes in morbidity. Callander E, editor. PLoS One. 2018;13(8):e0201697.

19. Hazra NC, Rudisill C, Gulliford MC. Determinants of health care costs in the senior elderly: age, comorbidity, impairment, or proximity to death? Eur J Heal Econ. 2018;19(6):831-42.

20. Kelley AS, McGarry K, Fahle S, Marshall SM, Du Q, Skinner JS. Out-of-pocket spending in the last five years of life. J Gen Intern Med. 2013;28(2):304-9.

21. Wang H, Otoo N, Dsane-Selby L. Ghana National Health Insurance Scheme: Improving Financial Sustainability Based on Expenditure Review. The World Bank; 2017. Available from: http://elibrary.worldbank.org/doi/book/10.1596/978-1-4648-1117-3

22. Blanchet NJ, Fink G, Osei-Akoto I. The Effect of Ghana's National Health Insurance Scheme on Health Care Utilisation. Ghana Med J. 2012;46(2):76.

23. Luginaah I, Arku G, Baiden P. Housing and health in Ghana: the psychosocial impacts of renting a home. Int J Environ Res Public Health. 2010;7(2):528-45.

\section{Figures}




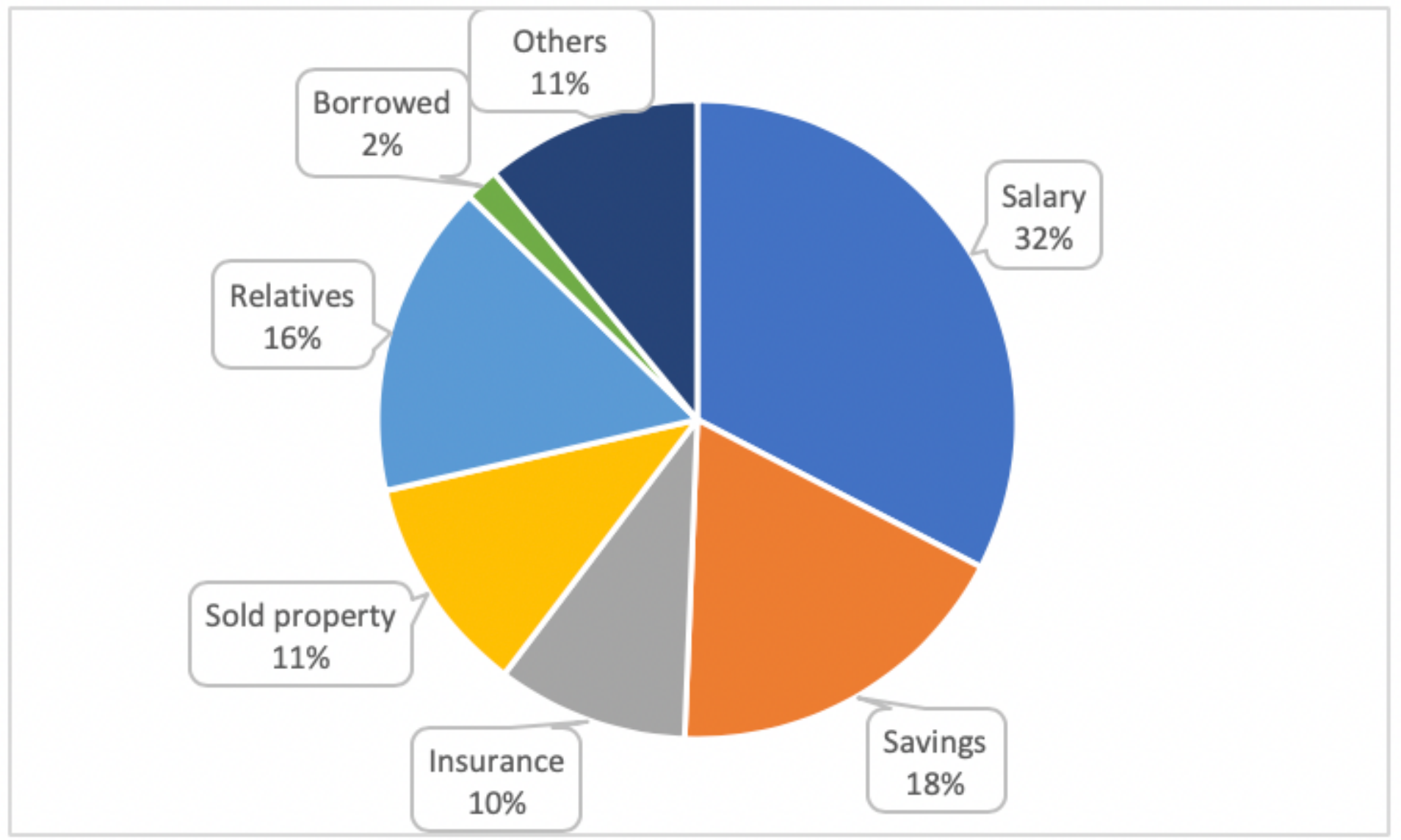

Figure 1

Sources of financing among the elderly in Ghana 


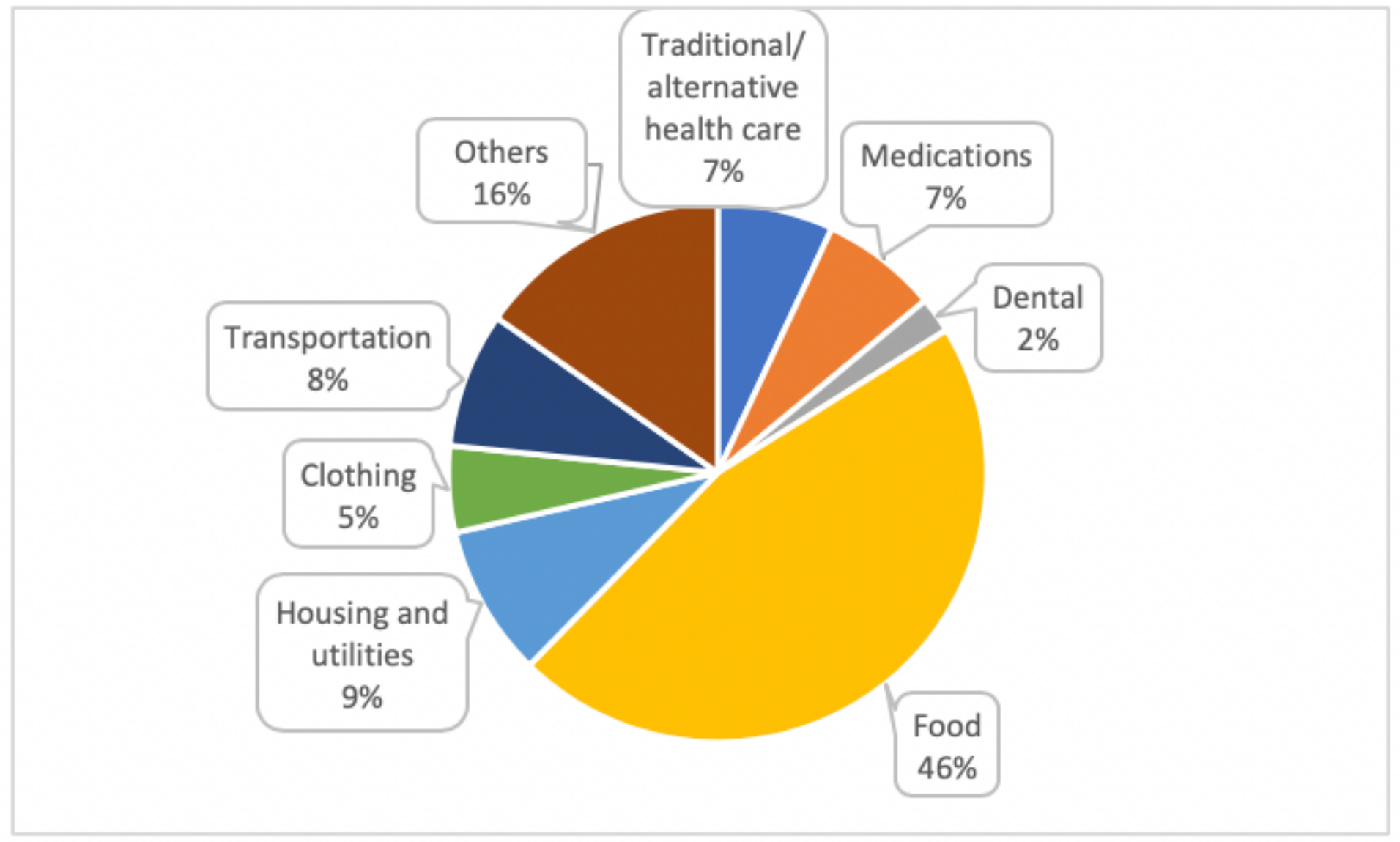

Figure 2

Proportions of cost areas among the elderly in Ghana 